\title{
Christian Belin (dir.), La méditation au XVIIe siècle.
} Rhétorique, art, spiritualité

Paris, Honoré Champion, coll. «Colloque, congrès et conférences sur le Classicisme », 6, 2006, $271 \mathrm{p}$.

Daniel-Odon Hurel

\section{CpenEdition}

Journals

Édition électronique

URL : http://journals.openedition.org/assr/5312

DOI : $10.4000 /$ assr.5312

ISSN : $1777-5825$

Éditeur

Éditions de l'EHESS

Édition imprimée

Date de publication : 1 juin 2007

Pagination : 97-251

ISBN : 978-2-7132-2143-9

ISSN : 0335-5985

Référence électronique

Daniel-Odon Hurel, « Christian Belin (dir.), La méditation au XVIle siècle. Rhétorique, art, spiritualité », Archives de sciences sociales des religions [En ligne], 138 | avril - juin 2007, document 138-5, mis en ligne le 11 septembre 2007, consulté le 21 septembre 2020. URL : http://journals.openedition.org/ assr/5312 ; DOI : https://doi.org/10.4000/assr.5312

Ce document a été généré automatiquement le 21 septembre 2020.

(c) Archives de sciences sociales des religions 


\section{Christian Belin (dir.), La méditation au XVIIe siècle. Rhétorique, art, spiritualité}

Paris, Honoré Champion, coll. « Colloque, congrès et conférences sur le Classicisme », 6, 2006, $271 \mathrm{p}$.

\section{Daniel-Odon Hurel}

La méditation est, à la fois, une notion un peu vague et une pratique culturelle et religieuse particulièrement importante aux $\mathrm{XVI}^{\mathrm{e}}$ et $\mathrm{XVII}^{\mathrm{e}}$ siècles. Le présent ouvrage collectif envisage de retrouver la ou les définitions de la méditation à cette période, en prenant appui sur les textes historiques et l'héritage patristique et médiéval. En se diffusant hors du cloître, la méditation s'est aussi accompagnée d'une individualisation plus grande du comportement religieux et spirituel des fidèles par rapport à l'Église d'où, sans doute en partie, la multiplication des méthodes destinées à encadrer cette dimension individuelle de l'épanouissement spirituel des religieux et surtout des laïcs. En ce sens, le succès de la pratique méditative pourrait avoir un lien avec le processus de laïcisation de la société même si l'idée que le xvIII ${ }^{\mathrm{e}}$ siècle « ne croit plus guère » (p. 8) peut être discutée à la lecture des travaux les plus récents en matière d'histoire religieuse. Une douzaine de contributions tentent d'analyser la méditation elle-même entre réformes et crise quiétiste (Ch. Belin), son évolution à partir de l'héritage monastique et médiéval (Benoît, Anselme) jusqu'à la défense par l'Oratoire et PortRoyal de l'exercice méditatif en passant par l'impact ignacien et carmélitain. Plus qu'une introduction, cette mise au point permet ensuite l'examen successif de la méditation dans un ensemble de situations socioculturelles, littéraires et artistiques propres au XVII ${ }^{\mathrm{e}}$ siècle : la tradition calviniste méditative sur les psaumes à partir des Méditations sur les psaumes d'Agrippa d'Aubigné (V. Ferrer), la place de la méditation dans l'éloquence et dans la vie parlementaire (B. Petey-Girard), la notion de tripartition de la méditation (mémoire, intelligence et volonté) dans la méditation jésuite (R. Dekoninck), la perspective polémique (la méditation au cœur des débats entre contemplation et méditation) qui s'appuie aussi sur un repérage et sur une analyse des 
modalités communes d'écriture des méditations (R. Parish), permettant en outre de comparer la pratique et le sens donné à la méditation chez Descartes et chez Malebranche (H. Courtès). Le concept de méditation ne s'inscrit pas uniquement dans les méthodes et les textes méditatifs énoncés comme tels. La poésie l'utilise (V. Adam) tout comme la tragédie (G. Forestier) et le roman spirituel (N. Grande) lorsque sont exprimés des sentiments autobiographiques, des analyses intérieures, la dimension morale de certains vers, pages ou scènes. Les liens entre méditation et peinture restent à la fois évidents et ambigus mis à part le soutien que le tableau peut apporter à l'imagination dévote, soutien envisagé chez Thérèse d'Avila mais non chez Ignace de Loyola (A. Le Pas de Sénéchal). Reste la question de la musique. Sans doute, certains motets et pièces musicales paraliturgiques (encadrant en particulier la dévotion au saint sacrement) et des pièces comme les Leçons de ténèbres peuvent contribuer à nourrir une méditation momentanée sans que l'on puisse pour autant distinguer méditation en musique et musique incitant à la méditation (A. Piéjus) comme le montre aussi un genre musical plus spécifiquement italien, les « vanités » (M. Suemi Lemos).

2 Cet ouvrage auquel on peut ajouter, pour mémoire, un autre ouvrage récent du même Ch. Belin (La conversation intérieure, publié en 2002 toujours chez Champion) ouvre des perspectives de premier intérêt pour l'histoire du fait religieux dans le christianisme moderne à partir d'une pratique et de sources encore peu étudiées malgré une omniprésence dont les historiens ont bien entendu conscience. 